\title{
Nonstationary probability processes, event runs, and the development of patterned response habits'
}

JOSEPH HALPERN and ALMA E. LANTZ,
University of Denver, Denver, Colo. 80210

A nonstationary probability process, which included variable runs of homogeneous events, was employed to examine patterning behavior in the uncertain-outcome/binary-decision task. The results showed that specific types of response patterns occurred which appeared to support an assumption that choice behavior was directed by discrete trial reinforcement effects. Further analyses demonstrated that the results were most accurately described by the formation of concepts leading to specific types of response patterning effects.

Anderson (1964) has emphasized the importance of the sequential structure of event outcomes in uncertain outcome prediction tasks. Research concerned with this event structure shows that specific types of response strategies, which are manifested in stable response patterns, of ten develop as a function of the reinforcement structure (e.g., Derks, 1963; Restle, 1966). Halpern, Lantz, \& Schwartz (1969) have shown that event outcomes serve as discriminative cues and that they appear to be as robust as more traditional discriminative stimuli (e.g., auditory cues). It appears likely that a wide range of "patterned" responding can be obtained if the appropriate event structure is employed. Further, random sequences will likely contain such discriminative substructures (run cues) which will influence choice behavior.

The present experiment represents a further attempt to define the role of the reinforcing event in choice behavior. A binary-choice decision task with nonstationary probability processes was employed. Such nonstationary processes involve situations where relative event frequencies change over trials. Similar procedures have been employed to evaluate theoretical models of choice behavior (Friedman, Burke, Cole, Keller, Millward, \& Estes, 1964). Anderson (1964) has suggested that nonstationary processes will result in marked discriminative contingencies across events. Further, if long runs of homogeneous events were involved, these would tend to induce response perseveration.

A procedure similar to that employed by Halpern et al (1969) was used in order to assess the strength and degree of patterning behavior induced by nonstationary probability processes that included short and long runs of homogeneous events Further, clear discriminative cues in the form of auditory stimuli were present so as to assess the relative power of the run cue.

\section{SUBJECTS}

The Ss were 90 University of Denver undergraduate volunteers, randomly assigned to three groups of 30 . APPARATUS

Up to four Ss were run at a time. The apparatus was similar to that used by Halpern et al (1969). Each $S$ was seated before a board consisting of a white warning light, two red event lights, and two spring-loaded switches. Audio stimuli were generated by an audio oscillator and modulated by two attenuators. Tones were presented over calibrated headphones. Experimental events were recorded on a strip chart digital recorder. Event and tone sequences were controlled by a micrologic module and a continuous white noise of $60 \mathrm{~dB}$ SPL was fed through the headphones.

\section{PROCEDURE}

Previous research (Halpern et al, 1969) established that tones of 65 and $61 \mathrm{~dB}$ SPL when evaluated with respect to $a$ comparison stimulus of $70 \mathrm{~dB}$ SPL, would result in proportions of responses of "differert" equal to .71 and .99 , respectively. Therefore, comparison stimuli of 70,65, and $61 \mathrm{~dB}$ SPL defined situations of high, medium, and low stimulus similarity, respectively. All tones were presented at $800 \mathrm{~Hz}$.

Each trial was initiated by one of two tones. The tones and the events were correlated. Thus, the occurrence of either tone would signal, with a greater-than-chance probability, the occurrence of one of the two events. The probability of an $E_{1}$ given either tone $\left(T_{i}\right)$, $P\left(E_{1} \mid T_{i}\right)$, varied randomly over a continuous interval from .60 to .80 in blocks of 30 trials. Thus, each $\mathrm{S}$ experienced 13 blocks of trials where $P\left(E_{1} \mid T_{1}\right)$ and $P\left(E_{1} \mid T_{2}\right)$ would be different within a block and each would vary independently across blocks. The overall $P\left(E_{1}\right)$ on any given block of trials was varied randomly and the maximum difference between $P\left(E_{1} \mid T_{1}\right)$ and $P\left(E_{1} \mid T_{2}\right)$ was .20 so that the former could equal .60 and the latter equal .80 , and vice versa. The minimum difference between the two was .05 . Since each $S$ received a total of 390 trials, there were 195 trials with cach tone. The relatively large $N$ in each group served to insure a representative sample of the range of $P\left(E_{1} \mid T_{i}\right)$, and the sequence of tones and events was different for each experimental session. The sequences were structured so that the shortest runs of homogeneous events tended to occur with the lowest $P\left(E_{1} \mid T_{i}\right)$ and the longest runs with the highest probabilities. The size of the run could vary from four to nine with the probability of a run of four or more homogeneous events equal to .09 during a .60-trial block and to .69 on trial blocks where $P\left(E_{1} \mid T_{i}\right)=.80$.

Each trial consisted of the presentation of one of two tones for $.5 \mathrm{sec}$, a warning signal light occurring $1.7 \mathrm{sec}$ after the onset of the tone, and a reinforcing light occurring $1.7 \mathrm{sec}$ after the onset of the warning signal, its duration being $1.6 \mathrm{sec}$. Total time per trial was a constant $5 \mathrm{sec}$ with a constant 3-sec intertrial interval. The Ss were instructed to respond after the onset of the warning signal and to make as many correct responses as possible. Reference to the discriminative aspects of the task were avoided. The position of the more frequently reinforced response alternatives was varied randomly across all Ss, and the more frequent event was always designated as $A_{1}$.

\section{RESULTS AND DISCUSSION}

Preliminary analyses showed that choice behavior, after approximately the first 100 trials, was virtually identical for all conditions of tonal cue similarity. The tones, then, were largely ignored after some initial experience. This was likely due to the constantly shifting reinforcement contingencies associated with the tones. Consequently, Table 1 gives the response probabilities conditional only on the

Table 1

First Order Conditional Probabilities for All Ss for the Last 210 Trials*

Probability

\begin{tabular}{|c|c|c|}
\hline$P\left(A_{1, n} \mid A_{1, n-1} E_{1, n-1}\right)$ & .95 & $(11,546)$ \\
\hline$P\left(A_{1, n} \mid A_{2, n-1} E_{1, n-1}\right)$ & .93 & $(1,162)$ \\
\hline$P\left(A_{1, n} \mid A_{1, n-1} E_{2, n-1}\right)$ & .09 & $(1,243)$ \\
\hline$P\left(A_{1, n} \mid A_{2, n-1} E_{2, n-1}\right)$ & .05 & $(4,859)$ \\
\hline
\end{tabular}

*Values in parentheses are frequencies summed across $A_{1}$ and $A_{2}$ responses.

Table 2

$P\left(A_{1, n}\right)$ as a Function of the Events on Trials $n-1$ and $n-2$

\begin{tabular}{lll} 
& \multicolumn{2}{c}{ Probability } \\
\hline$P\left(A_{1, n} E_{1, n-1} E_{1, n-2}\right)$ & .98 & $(10,324)$ \\
$P\left(A_{1, n} E_{1, n-1} E_{2, n-2}\right)$ & .97 & $(2.194)$ \\
$P\left(A_{1, n} E_{2, n-1} E_{1, n-2}\right)$ & .07 & $(1.926)$ \\
$P\left(A_{1, n} E_{2, n-1} E_{2, n-2}\right)$ & .01 & $(4,276)$ \\
\hline
\end{tabular}


I:able 3

Response Perseveration and Mlternation as a tunction of the Preceding Run of llomogeneous Events

\begin{tabular}{|c|c|c|c|c|c|c|c|c|}
\hline & $m=2$ & $\therefore$ & 4 & 5 & 6 & 7 & 8 & 9 \\
\hline$P\left(A_{i, n}, \lambda_{j, n-1} l_{i, n} \quad l_{j, n \rightarrow n}\right)^{*}$ & .44 & .93 & .96 & .97 & .94 & .93 & .94 & .96 \\
\hline$P\left(A_{i, n} \mid A_{j, n-1} E_{j, n} 1 E_{j, n \rightarrow 11}\right)$ & .04 & .03 & .01 & .03 & .05 & .04 & .07 & .03 \\
\hline
\end{tabular}

* The nototion " $n \rightarrow m$ " refers to $n-2$ for $m=2 n-2$ and $n-3$ for $n=3$. che:

response and event of the preceding trial. These first-order conditional response probabilities are based on data generated by all $90 \mathrm{Ss}$ for the last 210 trials. The data showed that whatever learning occurred did so relatively rapidly. and that choice behavior was clearly stable over the final 210 trials.

The first order conditional response probabilities in Table 1 provide some support for a stimulus sampling theory. The theory predicts $P\left(A_{1, n} \mid A_{1, n-1} E_{1, n-1}\right)$ to be greater than either $P\left(A_{1 . n}\right)$ $\left.A_{2, n-1} E_{1, n}\right)$ or $P\left(A_{1, n} \mid A_{1, n-1}\right.$ $\left.E_{2, n-1}\right)$ and that the latter conditionals be greater than $P\left(A_{1, n} \mid A_{2, n-1} E_{2, n-1}\right)$. Further, the reinforcement effect appears rather marked in that $P\left(A_{1, n}\right)$ was a good deal larger subsequent to $E_{1, n}$ - than after $\mathrm{E}_{2, \mathrm{n}-1}$.

Table 2 gives the $P\left(A_{1, n}\right)$ conditional only on the events of the two preceding trials. Again, response probability is seen to be heavily influenced by the event but the influence appears to be limited only to the preceding trial. The table exhibits an almost classic form of a one-trial dependent positive recency effect. Tables 1 and 2 demonstrate the virtual absence of any negative recency. Interpretation of these data is difficult because of the problem in separating negative recency from response alternation, and positive recency from response perseveration. The recency phenomena refer to response tendencies under the apparent control of discrete events, while alternation and perseveration are presumably reflections of response patterns induced by the event structure. One method of determining whether the present data are best characterized in terms of recency phenomenon or the result of some patterned response process, is to categorize response probabilities as a function of runs of homogeneous events. Such a categorization is provided in Table 3. The first expression in the table gives the probability of a response shift (response alternation) subsequent to an event shift as a function of the run of preceding homogeneous events. The entries show large and consistent response shifts with event shifts on the preceding trial. The behavior appears to be largely independent of the size of the run. If events were operating in some discrete manner as "reinforcements," then one would expect some consistent increase in $P\left(A_{i}, n\right)$ with increased run length. The second expression in Table 3 shows the probabilities of response shifts, in the absence of preceding event shifts, to be uniformly low.

Table 3, then, shows certain regularities in response patterns which provide support for an assumption that choice behavior was most heavily influenced by the sequential sincture of the event outcome. That is, Ss followed runs, and this run-following resulted in a specific type of response pattern that included response perseveration along with a one-trial event dependence. It would be misleading to conclude that the event outcome served as a reinforcer. A more accurate description might involve some concept-formation notion. The specific concept would include the assumption of an expectancy of a run, and the occurrence of the run would result in reinforcement of the expectancy. In this case, the specific concept could be described in terms of response perseveration and a one-trial event dependence.

If one conceives of the typical probability learning situation as an ambiguous task where Ss are actively engaged in a search for discriminative cues, then the situation is made even more ambiguous by nonstationary probabilities. The resultant nonindependent event contingencies inherent in any departure from the random
50:50 schedule provide the $\$$ with an applorent discrminative cele. The rapudity witl, which the lonal cue was disregarded here is an indicant of the mherent altractiveness of the run tire. Similat anditors stimuli have been slown m be most eflective discriminative cues in probability learning lasks that have used stationary processes (e.g.. Halpern \& Moore. 11)67).

The results demonstrate the polent effects of the event structure as opposed to the singular effects of the events. A clear suggestion is that events do not function as reinforeers in the traditional sense but rather that they aid in the developenent of a concept or expectancy which can result in very specific response patterns. Further, theoretical models of choice behavior such as those proposed by Restle (1966) and Gambino \& Myers (1967), that emphasize the importance of the run structure, would appear to show more potenial than the more traditional models which emplrasice the reinforcing properties of discrete events.

\section{RI:IERENCHS}

ANDERSON, $N$. H, An evaluation of stimulus sumpling theory: Comments on Professor fistes" paper. In A. W. Melton (lid.), Categories of human learning. Now York: Acadernic Pross. 1964

DERKS, P. L. Leffect of run length on the "gambler's fallacy." Joumal of lixperimental Psychology. 1963.65. 212-213.

IRIEDMAN. M. P., BLIRKI C I. COLL, M., KFLLER. L.. MILLWARD. R.B..\& ESTISS,W. K. Two-choice behavior under extended Iraining with shifting probabilitics of reinforcement. In R. C. Atkinson (lid.), Studies in mathematical psychology. Stonford: Stanford University Press, 1964.

GAMBINO. B.. \& MYERS, J.C. Role of event runs in probability learning. Psychological Revicw. $1967,74,410-419$.

HALPERN, J., LANTZ, A. E., \& SCHWARTZ. J. A. Cuc propertics of the event run in choice discrimination learning. Journal of Experimental Psychology, 1969, 80, 237-242.

HALPIRN, J.. \& MOORl:. J. W. Two-choict discrimination learning as a function of cue similarity and probability of reinforcement. Journal of Expcrimental Psychology, 1967,74, 182-186.

RESTLE. F. Run structure and probability learning: Disproof of Restle's model. Journal of Experimental Psychology. 1966. 72, 382.389. NOTE

1. This rescarch was supported by National Institute of Mental Health Grant MH I4102-0I. 